\title{
Finite Element Analysis of the Space Energy Distribution of Incinerator
}

\author{
Chenglin Du* , E Liu and Fangfang Jian \\ Qingdao University of Science and Technology Qingdao 266061, China \\ *Corresponding author
}

\begin{abstract}
In view of the cracking furnace in the wastes tires, both inside and outside the study of the energy produced by induction coil. Electromagnetic induction coil and the cracking furnace finite element model is established.Using the software of ansys simulation of induction coil into the current work.The change rule of the electromagnet-field, eddy current field in the cracking furnace .In order to gain access into the coil current and eddy current relationships within the cracking furnace curve.
\end{abstract}

Keywords-cracker; electromagnetic; spaceener gydistribution

\section{INTRODUCTION}

With the development of industrial and agricultural production and transportation ,the number with the development of industrial and of waste tires and all kinds of waste rubber products more and more. Waste tyre deposited in the open air for a long time not only takes up a up a lot of land, and mosquito breeding ground for infectious diseases , also easy to cause fire, the "black pollution " caused by waste tires is a very serious problem .

At present, the waste rubber recovery rate of about $47 \%$ a year, is a below aver agelevel ,Below average level the recycling of waste tires is about $80 \%$,using waste tire rubber powder and renovation is not the final approach These rubber products after use for a long time, still can cause secondary pollution .

At present, the cracking of waste tires pyrolysis technology is most null But due to the large energy consumption , such problems as incomplete pyrolysis is not the optimal choice . In this paper the analysis of the cracking furnace is cracking by light waves There is little energy consumption , cracking degree is high , high recovery rate of the product.

\section{THE EstABLISHMENT OF THE SUB-MODEL}

Geometric model of incinerator was established by using AutoCAD and SolidWorks, then import the model into the ANSYS Workbench, Composite model of the incinerator was built by using the ACP module of the ANSYS Workbench, assembled with the stainless steel part, finally established the finite element model of incinerator.

Based on multiscale finite element analysis theory[3], in the bead we set a radius for $2 \mathrm{~mm}$ semicircular three-dimensional crack, using 20 node SOLID186 unit .In ANSYS Workbench, the part of out wall of incinerator were built as sub-model, as shown in Figure 1 The location of sub-model, 2 Sub-model with coil and 3 Sub-model with applied internal heat generation.

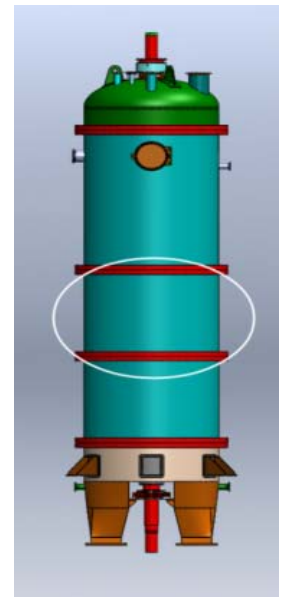

FIGURE I. THE LOCATION OF SUB-MODEL

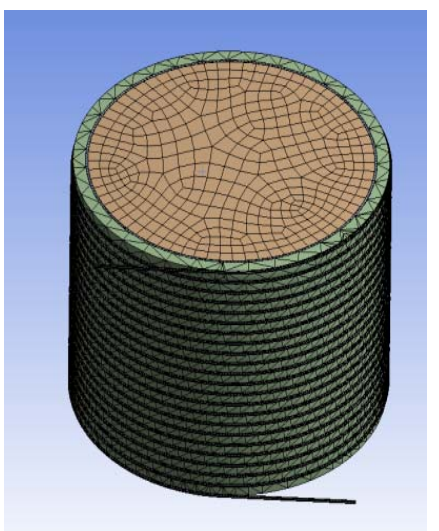

FIGURE II. SUB-MODEL WITH COIL

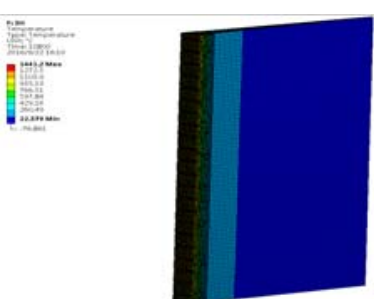

FIGURE III. SUB-MODEL WITH APPLIED INTERNAL HEAT GENERATION 
III. RESEARCH METHOD OF TIRE SPACE ENERGY DISTRIBUTION PROPAGATION

In this paper, the energy method of space energy distribution propagation was used to study the temperature field in the incinerator, and the transient thermal were used to measure the rubber temperature.

\section{The Rubber Particles in 180KW Power Heating TEMPERATURE VARIATION IN DIFFERENT TIME}

Currently on the market to provide the biggest waves of transmitter power up to $250 \mathrm{kw}$ but in actual use in about 180 $\mathrm{kw}$ So in the analysis of the selected $180 \mathrm{kw}$ of power is analyzed. Analysis under the condition of the power of different heating time Basically see the inside of the furnace body temperature of rubber particles because of the rubber particles and decomposition reaction decomposition gas separation requires a certain temperature Avoid duplication of reaction, reduce the reaction efficiency.

From figure 4 to figure 9 below corresponding to work an hour to 6 hours.
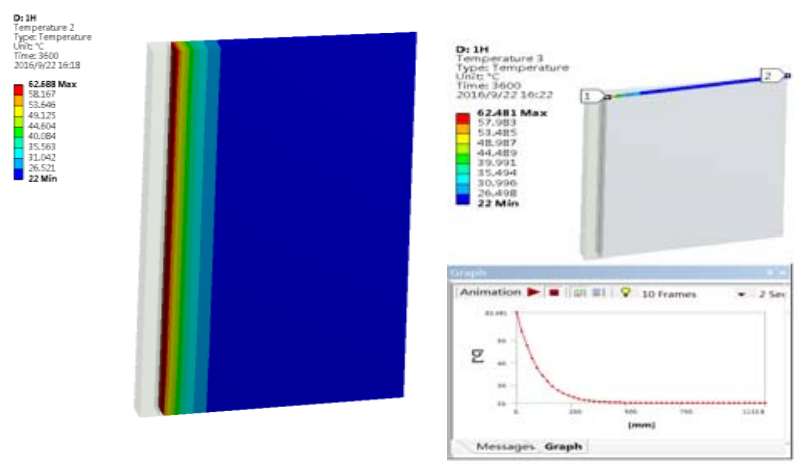

FIGURE IV. HEAT FOR 1 HOUR
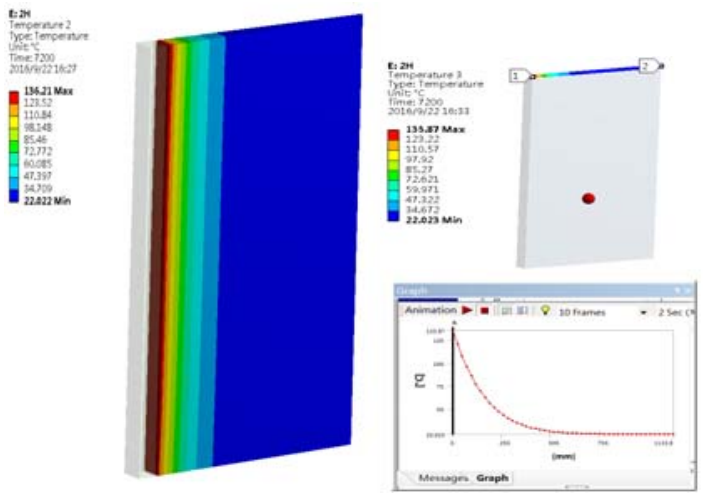

FIGURE V. HEAT FOR 2 HOUR

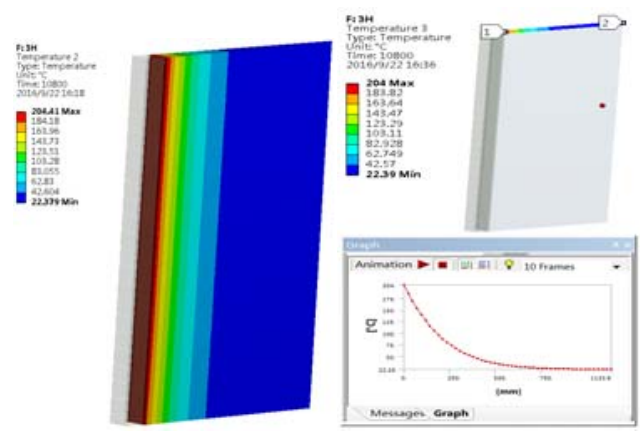

FIGURE VI. HEAT FOR 3 HOUR

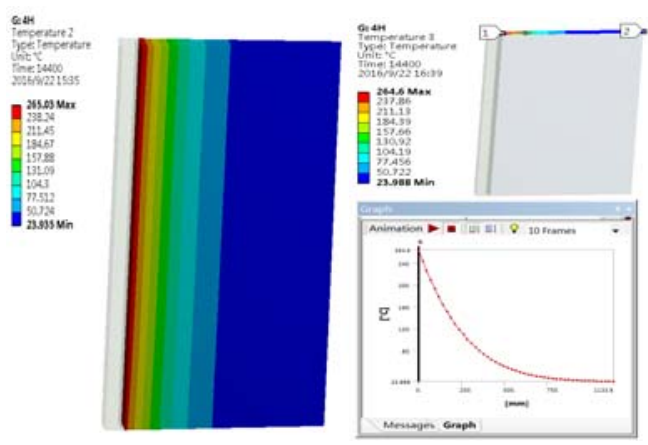

FIGURE VII. HEAT FOR 4 HOUR

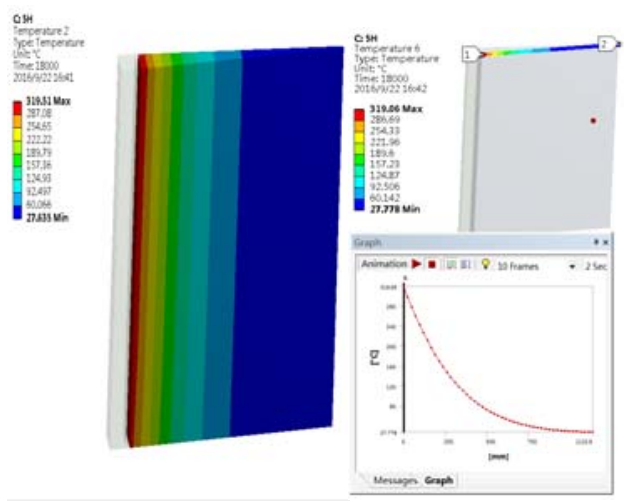

FIGURE VIII. HEAT FOR 5 HOUR

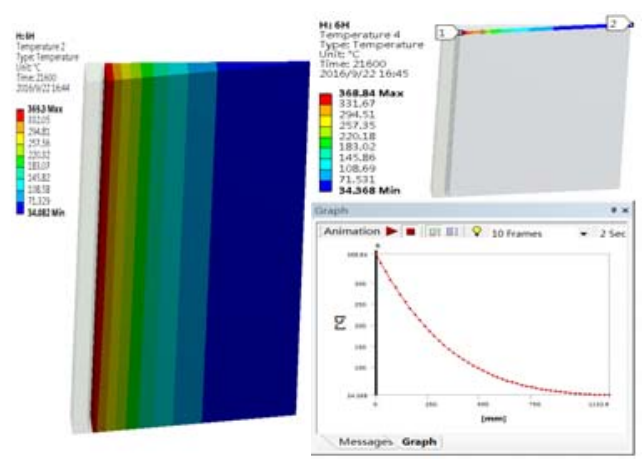

FIGURE IX. HEAT FOR 6 HOUR

Figure10 is the rise of temperature of the rubber particles change with time curve. Start temperature rise faster, when 
temperature of $300^{\circ} \mathrm{C}$ or so basic remain unchanged, Can be seen through the curve. The reason may be that the reaction temperature has been reached part of materials react to absorb heat so roughly in balance.

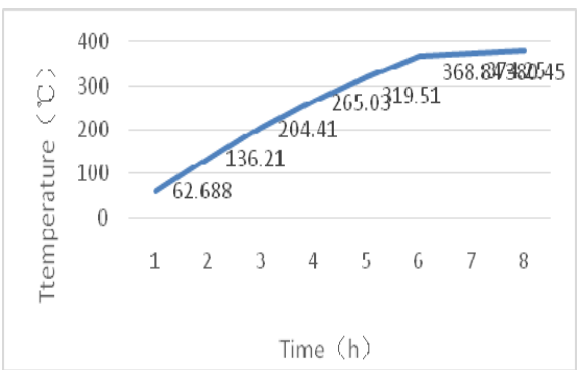

FIGURE X. THE CURVE OF TEMPERATURE IN DIFFERENT TIME

\section{LIFE AsSESSMENT OF THE THICKNESS OF THE TEMPERATURE RISE}

In the process of incinerator design the thickness is a very important parameter . If thickness will cause the temperature of the reaction cavity part material reach reaction temperature resulted in incomplete .The end result is a waste of resources and the secondary pollution ,If the thickness is too small will led wasted of energy and reduce the rate of reaction .So by analyzing the distribution of the amount of the cross section, to design the thickness of the reaction chamber. Figure 11 is under the condition of the different heating time temperature with the increase of the thickness of the temperature change curve.

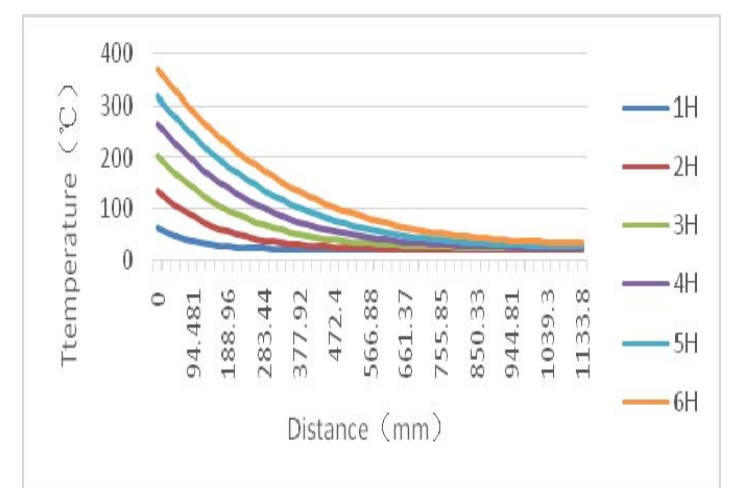

FIGURE XI. THE CURVE OF TEMPERATURE IN DIFFERENT DISTANCE

\section{CONCLUSION}

In this paper, the finite element analysis software ANASYS of cracking furnace wall of the coil in the furnace walls to simulated analysis of the eddy current .Intuitive reaction within the reactor magnetic induction intensity $\mathrm{B}$ and the size of the eddy current density distribution .Simulated under different frequency of the change of the coil in the magnetic field and eddy current field in the reactor .The results showed that ,The increase in the frequency of the alternating current coil, the coil is less to produce the magnetic field strength in the cracking furnace ;Cracking furnace in the eddy current density increases with the increase of alternating current frequency .And Under the same frequency at different times of temperature changes

For the cracking furnace ,Inside the furnace wall to produce the size of the eddy current and magnetic field intensity in the furnace is of concern to us ,The conclusions obtained in this paper is for further study on light waves of pyrolysis of organic macromolecular cracking furnace designed to provide some theoretical basis.

\section{ACKNOWLEDGMENT}

This work was supported by the Project of science and technology project of National 863 plans projects of Chain (2012AA000100).

\section{REFERENCES}

[1] chang shi jia. Injection machine cylinder electromagnetic induction heating temperature mathematical model and numerical simulation research[D ]. Beijing University of Chemical Technology 2010:11 36

[2] fu zheng bo. Design and application of induction heater [M]. Beijing: China Machine Press 2008:11 36

[3] Jiang Shan. Some Studies and Applications on the Multiscale Finite Element Method[D]. Xiangtan University,2008

[4] RMA . Scrap Tire Markets in the United States 2005 Edition[R]. Washington DC,USA:Rubber Manufacturers Association,2006

[5] Leung DYC, Wang CL.kinetic modeling of scrap tire Pyrolysis .Energy Fuel,1999,13(2):421 427

[6] G. Eason, B. Noble, and I. N. Sneddon, "On certain integrals of Lipschitz-Hankel type involving products of Bessel functions,” Phil. Trans. Roy. Soc. London, vol. A247, pp. 529-551, April 1955. (references)

[7] J. Clerk Maxwell, A Treatise on Electricity and Magnetism, 3rd ed., vol. 2. Oxford: Clarendon, 1892, pp.68-73.

[8] I. S. Jacobs and C. P. Bean, "Fine particles, thin films and exchange anisotropy,” in Magnetism, vol. III, G. T. Rado and H. Suhl, Eds. New York: Academic, 1963, pp. 271-350. 